\title{
Differential expression levels of urokinase-type plasminogen activator and cathepsin $D$ in locally advanced laryngeal squamous cell carcinoma: clinical implications
}

\author{
G. Leto ${ }^{1}$, F.M. Tumminello ${ }^{1}$, N. Gebbia ${ }^{1}$, V. Bazan ${ }^{2}$, R.M. Tomasino ${ }^{3}$, G. Dardanoni ${ }^{4}$, A. Russo ${ }^{2}$ \\ ${ }^{1}$ Laboratory of Chemotherapy and Tumor Markers and ${ }^{2}$ Laboratory of Experimental Oncobiology, Service of \\ Chemoterapy, Regional Reference Center for Biomolecular Characterization of Neoplasms and Genetic Screening of \\ Hereditary Tumors \\ ${ }^{3}$ Institute of Pathology "R", Policlinico P. Giaccone, Palermo \\ ${ }^{4}$ Epidemiologic Observatory Center, Regione Sicilia, Palermo - Italy
}

\begin{abstract}
The expression levels and the prognostic impact of urokinase-type plasminogen activator (uPA) and cathepsin D (CD) were evaluated in patients with locally advanced laryngeal squamous cell carcinoma (LSCC). uPA and CD protein levels were determined by immunoluminometric or immunoenzymatic assays in the cytosol of paired sets of tumor tissues and corresponding adjacent normal mucosa (NLM) from 57 patients with stage III/IV LSCC and were correlated with a number of clinicobiological parameters of this tumor including anatomical site, tumor grade, nodal status, clinical stage, DNA ploidy, proliferation rate, and patient outcome. Median uPA levels were significantly higher in LSCC than in NLM $(1.8 \mathrm{ng} / \mathrm{mg}$ of protein vs $0.3 \mathrm{ng} / \mathrm{mg} ; \mathbf{p}<0.001)$ whereas median CD levels were not significantly increased in tumor tissue compared to NLM (24 pmol/mg vs $19 \mathrm{pmol} / \mathrm{mg}$, p=0.063). No significant correlation was observed between uPA and CD concentrations in tumor tissues $(r=-0.1 ; p=0.4)$. Furthermore, the distribution analysis of $u P A$ and $C D$ in tumors showed no correlation between expression levels of these proteinases and the parameters mentioned above including patient outcome. However, when data were matched according to each parameter examined it was observed that the differences in uPA content between LSCC and NLM, expressed as uPA tumor/normal tissue ratio (T/M), were more marked in clinically advanced and/or aggressive forms of LSCC (i.e., node positive, stage IV, poorly and moderately differentated, aneuploid multiclonal, low S-phase, subglottis tumors). These data suggest that in such tumors altered regulation of uPA may occur to a greater extent than in less aggressive and less advanced forms of LSCC. This phenomenon was not observed for CD. However, in tumors with a high proliferation rate, in stage IV tumors as well as in those located in the supraglottis, CD levels were significantly higher than those found in the corresponding $\operatorname{NLM}(p=0.008, p=0.02$ and $p=0.03$, respectively). In conclusion, uPA is highly expressed in locally advanced LSCC and appears to be implicated in some key events of progression of this tumor such as local invasion and/or nodal involvement, whereas CD does not seem to have a role in promoting these processes. Nevetheless, neither of these proteinases seem to be prognostically useful in patients with stage III/IV tumors. (Int J Biol Markers, 2001; 16: 245-9)
\end{abstract}

Key words: Cathepsin D, Laryngeal carcinoma, Lysosomal proteinases, Serine proteinase, Tumor markers, Tumor progression, Urokinase-type plasminogen activator

\section{INTRODUCTION}

Serine proteinase urokinase-type plasminogen activator (UPA) and lysosomal aspartic proteinase cathepsin D (CD) have been suggested to promote, in concert with other proteolytic enzymes, the malignant progression of neoplastic diseases. In fact, the expression levels of these proteinases have been shown to be altered in tumor cells and tissues compared to their normal counterparts. This phenomenon appeared to be correlated with the onset of a more malignant tumor phenotype and, consequently, with a poor clinical prognosis $(1,2)$. Altered UPA and CD levels have also been observed in head and neck tumors including laryngeal squamous cell carcinoma (LSCC) (39), where, additionally, recent in vitro studies have shown that increased intracellular levels of both enzymes were associated with the onset of antitumor drug resistance (10). However, to our knowledge, specific studies aimed at investigating the correlation between uPA tumor levels and some specific clinicobiological pa- 
rameters of LSCC progression and aggressiveness including DNA ploidy and proliferation rate (S-phase fraction) $(11,12)$ are still lacking, while the prognostic significance of UPA in patients with locally advanced LSCC (stage III/IV) remains to be assessed. On the other hand, several clinical investigations have shown that in patients with early stage LSCC (stage I/II) increased CD tumor levels are associated with a poor clinical outcome (7-9). On the basis of these findings we have undertaken further studies to determine whether CD and uPA may be useful as biological markers to identify more aggressive forms of locally advanced LSCC and to evaluate their prognostic impact in patients with stage III/IV tumors.

\section{PATIENTS AND METHODS}

Our study included 57 patients with stage III/IV LSCC (56 males, 1 female; mean age 65.0 \pm 9.1 ) whose characteristics are shown in Tables II and III.

None of the patients had distant metastases. The median follow-up was 30 months (range 4-61). Tumors were staged according the American Joint Committee on Cancer Classification (13). DNA ploidy and proliferation rate (S-phase fraction) were determined as described in detail elsewhere $(11,12)$.

\section{Determination of cathepsin D and uPA levels in LSCC}

Matched paired sets of LSCC and adjacent NLM samples (40-200 mg) obtained at surgery as previously reported (12) and stored at $-80^{\circ} \mathrm{C}$ were thawed, minced and suspended at $25 \mathrm{mg} / \mathrm{mL}$ in a homogenization buffer (50 mM Tris- $\mathrm{HCl}, 5 \mathrm{mM}$ EDTA, $0.2 \% \mathrm{w} / \mathrm{v}$ Triton-X-100; $\mathrm{pH}$ 6.9). Samples were homogenized at $2^{\circ} \mathrm{C}$ and centrifuged at $400 \mathrm{~g}$ for $10 \mathrm{~min}$ at $4{ }^{\circ} \mathrm{C}$ as described elsewhere $(12,14)$. The post $400 \mathrm{~g}$ supernatant was then respun at $13,000 \mathrm{~g}$ for $15 \mathrm{~min}$ at $4^{\circ} \mathrm{C}$ in a preparative ultracentrifuge (Beckman, Model L8-80). The 13,000g supernatant («cytosol») was stored at $-80^{\circ} \mathrm{C}$ until assay. uPA levels were determined in the cytosol by a commercially available immunoluminometric assay kit (Byk Sangtec, Cormano, Italy). The monoclonal antibodies used bind either to the proenzyme or to the active form as well as to the enzyme bound to its receptor (UPAR) or to its endogenous inhibitor (PAI-1). The detection limit reported by the manufacturer was $<0.005 \mathrm{ng} / \mathrm{mL}$. Total $\mathrm{CD}$ content (i.e., the $52 \mathrm{kDa}$ proenzyme + the $34 \mathrm{kDa}$ mature form of the enzyme) was determined by a commercially available immunoenzymatic assay kit (Triton EIA CD kit, Ciba-Corning Diagnostic, Alameda, CA, USA). The detection limit reported was $0.018 \mathrm{pmol} / \mathrm{mL}$. Cytosol protein content was measured by a commercially available colorimetric micromethod assay kit (Sigma, St. Louis, MO, USA).

\section{Statistical analysis}

The median UPA and CD contents in NLM were taken as the cutoff levels. Significant differences between the median content levels of uPA or CD in matched pairs of LSCC and NLM were determined by Wilcoxon's signed rank test. Correlations between uPA and CD levels in tumor tissues were computed by the nonparametric Spearman rank correlation test. The nonparametric Mann-Whitney or Kruskall-Wallis tests were used, where appropriate, to assess the correlation between uPA or CD distribution in LSCC and nodal status, clinical stage, tumor grade, DNA ploidy, S-phase fraction and tumor site. The Kaplan-Meier (log rank) and multivariate Cox analyses were used to analyze survival, while the stepwise logistic regression analysis was used to evaluate the most significant independent prognostic parameters. The 0.05 level of probability was taken as significant.

\section{RESULTS}

uPA and $C D$ distribution in normal and tumor tissue samples

Median uPA levels were significantly higher in LSCC than in the corresponding adjacent NLM $(1.8 \mathrm{ng} / \mathrm{mg}$ protein vs $0.3 \mathrm{ng} / \mathrm{mg}$ protein; $p<0.001$ ), while median CD tumor levels were not significantly different from those determined in NLM (24 pmol/mg protein vs $19 \mathrm{pmol} / \mathrm{mg}$ protein; $\mathrm{p}=0.063$ ) (Table I). No significant correlation was observed between tumor-specific UPA and CD levels $(r=-0.11 ; p=0.42$, Spearman rank correlation test). Inter-

TABLE I - UPA AND CD CONTENT LEVELS IN LOCALLY ADVANCED LSCC AND PAIRED NORMAL LARYNGEAL MUCOSA (NLM) (n=57)

\begin{tabular}{llrrr} 
& \multicolumn{2}{c}{ uPA (ng/mg) } & \multicolumn{2}{c}{ CD (pmol/mg) } \\
& Median & (Range) & Median & (Range) \\
\hline NLM & 0.3 & $(0.1-2.2)$ & 19.8 & $(0-182.0)$ \\
LSCC & $1.8^{*}$ & $(0.02-9.6)$ & $24.0^{\circ}$ & $(1.0-95.3)$ \\
T/M & 7.9 & $(0.01-200)$ & 1.2 & $(0.13-168)$ \\
\hline
\end{tabular}

${ }^{*} \mathrm{P}<0.001$ and ${ }^{\circ} \mathrm{P}=0.063$ vs NLM (Wilcoxon signed rank test)

${ }^{\mathrm{a}} \mathrm{T} / \mathrm{M}=$ Median Tumor/NLM concentration ratio 
TABLE II - PATIENTS CHARACTERISTICS AND uPA TISSUE LEVELS (ng/mg protein) IN LOCALLY ADVANCED LSCC AND IN PAIRED NLM. DISTRIBUTION ACCORDING TO BIOLOGICAL AND CLINICAL PARAMETERS

\begin{tabular}{|c|c|c|c|c|c|c|}
\hline Parameter & No. of patients ${ }^{1}$ & LSCC & Pvalue & NLM & $\mathbf{T} / \mathbf{M}^{2}$ & Pvalue \\
\hline supraglottis & 16 & $2.6(0.27-6.4)^{*}$ & \multirow{2}{*}{ N.S. ${ }^{4}$} & $0.53(0.01-1.5)$ & $9.8(1.1-200)$ & \multirow{2}{*}{ N.S. ${ }^{4}$} \\
\hline subglottis & 3 & $2.4(1.5-7.1)^{*}$ & & $0.38(0.06-0.58)$ & $12.2(4.7-23.4)$ & \\
\hline \multicolumn{7}{|l|}{ Clinical stage } \\
\hline Stage III & 36 & $2.4(0.03-9.6)^{*}$ & \multirow[b]{2}{*}{ N.S. } & $0.41(0.04-2.0)$ & $7.2(0.01-71.6)$ & \multirow[b]{2}{*}{ N.S. } \\
\hline Stage IV & 21 & $1.4(0.03-9.1)^{*}$ & & $0.31(0.01-2.2)$ & $11.1(0.95-200)$ & \\
\hline node positive & 8 & $3.4(0.2-7.7)^{*}$ & \multirow[t]{2}{*}{ N.S. } & $0.35(0.04-0.6)$ & $9.8(1.8-16.0)$ & N.S. \\
\hline \multicolumn{6}{|l|}{ Tumor grade } & \\
\hline G1(well differentiated) & 8 & $2.2(1.4-5.4)^{*}$ & \multirow{3}{*}{ N.S. } & $0.56(0.2-1.1)$ & $3.4(2.0-13.9)$ & \multirow{3}{*}{ N.S. } \\
\hline G2(moderately differentiated) & 39 & $1.2(0.03-9.6)^{*}$ & & $0.41(0.01-0.64)$ & $9.2(0.01-200)$ & \\
\hline G3(poorly differentiated) & 10 & $1.2(0.02-6.4)^{\circ}$ & & $0.22(0.01-0.64)$ & $8.9(1.8-24.5)$ & \\
\hline \multicolumn{7}{|l|}{ DNA ploidy } \\
\hline$>13.9 \%$ & 27 & $1.6(0.03-9.1)^{\circ}$ & N.S. & $0.42(0.01-2.2)$ & $5.4(0.01-24.5)$ & N.S. \\
\hline
\end{tabular}

Data are shown as median and range. 'Due to some missing sample number of patients for each parameter may vary

${ }^{2} \mathrm{~T} / \mathrm{M}=$ Median Tumor/NLM ratio concentration. ${ }^{3}$ Cut-off level $=$ median S-Phase value in LSCC

${ }^{\circ} \mathrm{P}<0.05$ and ${ }^{*} \mathrm{P}<0.01$ vs NLM (Wilcoxon signed rank test).

${ }^{4} \mathrm{~N} . \mathrm{S} .=$ No significant correlation was observed between uPA tumor levels or T/M ratio values and the parameters considered

(Mann-Witney or Kruskall Wallis nonparametric tests)

TABLE III - PATIENTS CHARACTERISTICS AND CD TISSUE LEVELS (pmol/mg protein) IN LOCALLY ADVANCED LSCC AND PAIRED NLM. DISTRIBUTION ACCORDING TO BIOLOGICAL AND CLINICAL PARAMETERS

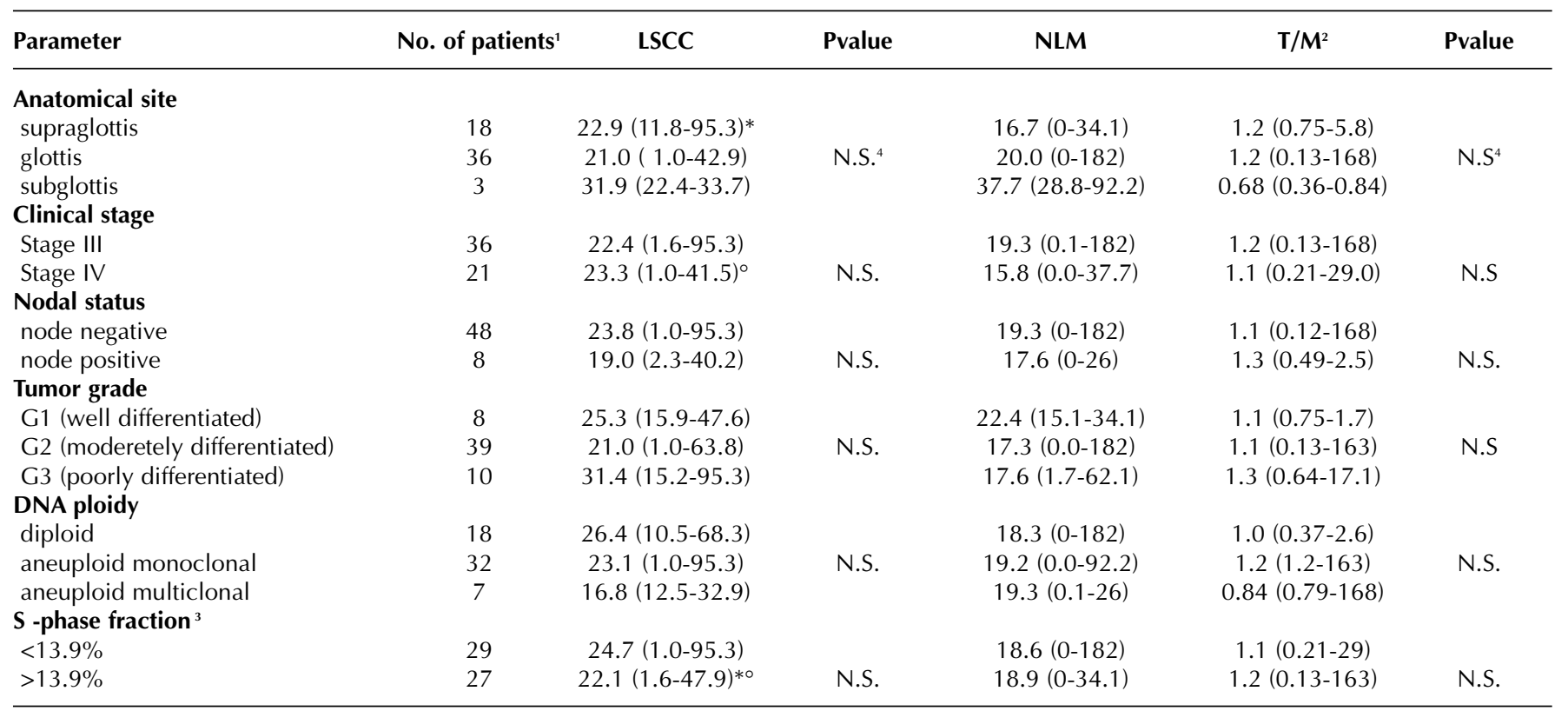

Data are shown as median and range. 'Due to some missing sample number of patients for each parameter may vary

${ }^{2} \mathrm{~T} / \mathrm{M}=$ Median Tumor/NLM ratio concentration. ${ }^{3}$ Cut-off level $=$ median S-Phase value in LSCC

$* \mathrm{P}=0.008,{ }^{\circ} \mathrm{P}=0.02$ and $\mathrm{P}=0.03$ vs NLM (Wilcoxon signed rank test).

${ }^{4} \mathrm{~N} . \mathrm{S} .=$ No significant correlation was observed between $\mathrm{CD}$ tumor levels or $\mathrm{T} / \mathrm{M}$ ratio values and the parameters considered

(Mann-Witney or Kruskall Wallis nonparametric tests) 
estingly, when data were matched according to each single parameter considered, the difference in UPA concentrations between tumor tissue and normal tissue, expressed as tumor/normal tissue ratio (T/M), was more marked in some clinically advanced and/or more aggressive forms of LSCC (Table II). In fact, while in aneuploid multiclonal tumors uPA levels were 12.2-fold higher $(\mathrm{T} / \mathrm{M}=12.2)$ than those measured in the corresponding NLM, in aneuploid monoclonal and in diploid tumors UPA levels were 4.7 and 8.4-fold higher than in NLM (Table II). Similarly, this phenomenon was present in tumors with a low Sphase fraction (i.e., less susceptible to chemotherapy or radiotherapy) ( $\mathrm{T} / \mathrm{M}=9.1$ vS $\mathrm{T} / \mathrm{M}=5.4$ in high $\mathrm{S}$ phase tumors), in stage IV tumors ( $\mathrm{T} / \mathrm{M}=11.1 \mathrm{vs}$ $\mathrm{T} / \mathrm{M}=7.2$ in stage III tumors), in node-positive tumors ( $\mathrm{T} / \mathrm{M}=9.8 \mathrm{vs} \mathrm{T} / \mathrm{M}=6.5$ in node-negative tumors), in moderately or poorly differentiated tumors $(\mathrm{T} / \mathrm{M}=9.2$ and $\mathrm{T} / \mathrm{M}=8.9$ vs $\mathrm{T} / \mathrm{M}=3.4$ in well differentiated tumors) and in tumors located in the subglottis $(\mathrm{T} / \mathrm{M}=12.2 \mathrm{vs} \mathrm{T} / \mathrm{M}=5.6$ and $\mathrm{T} / \mathrm{M}=9.8$ of tumors located in the glottis and the supraglottis, respectively) (Table II). These phenomena were not observed for CD (Table III). On the other hand, significant differences in CD content between tumor tissue and NLM were observed in highly proliferating tumors $(p=0.008)$, in stage IV tumors $(p=0.02)$ and in tumors located in the supraglottis $(p=0.035)$ (Table III). However, the distribution analysis of uPA and CD showed no statistically significant correlation between tumorspecific levels of both these proteinases and tumor site, nodal status, clinical stage, tumor grade, DNA ploidy and S-phase fraction (data not shown). Similar results were obtained when T/M values were evaluated (data not shown).

\section{Univariate and multivariate analysis}

Univariate analysis showed that neither uPA nor $C D$ tumor levels were prognostically relevant for disease-free survival $(p=0.23$ for $\mathrm{UPA}$ and $p=0.62$ for CD) and overall survival ( $p=0.95$ for $\mathrm{UPA}$ and $p=0.76$ for CD). In addition, Cox's multivariate analysis did not evidence any statistically significant impact of these enzymes either on disease-free survival (uPA: relative risk $=0.59 ; 95 \%$ confidence interval $\mathrm{Cl}$ $0.23-1.53 ; p=0.28 ; C D$ : relative risk $=0.76,95 \% \mathrm{Cl}$ $0.28-1.88 ; p=0.52$ ) or overall survival (uPA: relative risk $=1.22 ; 95 \% \mathrm{Cl} 0.36-5.18, \mathrm{p}=0.75 ; \mathrm{CD}$ : relative risk $=1.22 ; 95 \% \mathrm{Cl} 0.39-3.82 ; \mathrm{p}=0.73)$.

\section{DISCUSSION}

The present results show that a different pattern of expression of UPA and CD may be observed in lo- cally advanced LSCC. In fact, unlike the CD levels, median uPA levels were significantly increased in LSCC compared to its normal counterpart. These findings confirm previous observations by other authors (3-6) who demonstrated that UPA is upregulated in laryngeal tumors. In addition, our results show that this phenomenon is more marked in more aggressive and advanced forms of this tumor. These observations strongly support the hypothesis that uPA may be involved in some key events of LSCC progression such as local invasion and/or nodal involvement. On the other hand, unlike the results reported in other studies (15), our data failed to show any significant impact of uPA on the clinical outcome of these patients. These conflicting results may be explained in part by different patient selection in these studies as well as by the different numbers of patients used (15). Furthermore, our results did not evidence any significant correlation between tumor $C D$ levels and clinicobiological parameters of LSCC progression.

These findings partially agree with those observed by other investigators (15-17), who reported, in patients with head and neck tumors including LSCC, a lack of correlation between CD expression levels and some of the parameters considered in this study as well as patient survival. However, when the data were matched according to each parameter investigated it was observed that in tumors with a high proliferation rate as well as in stage IV tumors and in tumors located in the supraglottis, CD levels were significantly higher in tumor tissues than in the corresponding NLM, thus suggesting that an altered regulation of this enzyme may occur in these specific cases.

These results support the concept that CD is likely to facilitate events upstream of LSCC progression such as tumor cell proliferation and malignant transformation (18-20), and may also partly account for the significant correlation demonstrated by other studies between tumor $C D$ levels and poor prognosis in patients with early stage (I/II) LSCC (7-9). Interestingly, recent in vitro studies have shown that some drug-resistant human laryngeal tumor cell lines express higher levels of both uPA and CD than their parental tumor cell counterparts (10). These findings further indicate that altered intracellular levels of these enzymes seem to be associated with the onset of more malignant tumor phenotypes $(3,4,10)$. Therefore UPA, in concert with other well-established prognostic factors $(11,12,17,21)$, may be potentially useful as a biological marker to identify groups of patients with more aggressive forms of locally advanced LSCC being at risk of recurrence and resistance to clinical treatments. Further clinical studies are warranted by the present results. 


\section{ACKNOWLEDGEMENTS}

This work was supported by grants from the Italian Association for Cancer Research (AIRC), MURST 60\%, and in part by CNR, PF ACRO, SP4 (contract No. 96.00570.PF39).

Address for correspondence:

Dr. G. Leto

Viale Piemonte, 3

90144 Palermo, Italy

e-mail: Chemio@unipa.it

\author{
Abbreviations: \\ CD, cathepsin D \\ LSCC, laryngeal squamous cell carcinoma \\ NLM, normal laryngeal mucosa \\ $\mathrm{T} / \mathrm{M}$, tumor/normal tissue ratio \\ uPA, urokinase-type plasminogen activator
}

\section{REFERENCES}

1. Schmitt M, Harbeck N, Thomssen C, et al. Clinical impact of the plasminogen activation system in tumor invasion and metastasis: prognostic relevance and target for therapy. Thromb Haemostasis 1997; 78: 285-96.

2. Leto G, Gebbia N, Rausa L, Tumminello FM. Cathepsin D in the malignant progression of neoplastic diseases. Anticancer Res 1992; 12: 235-40.

3. Parolini S, Flagiello D, Cinquetti A, et al. Up-regulation of urokinase-type plasminogen activator in squamous cell carcinoma of human larynx. Br J Cancer 1996; 74: 1168-74.

4. Clayman G, Wang SW, Nicolson GL, et al. Regulation of urokinase-type plasminogen activator expression in squamous cell carcinoma of the oral cavity. Int J Cancer 1993; 54: 73-80.

5. Nozaki S, Endo Y, Kawashiri S, et al. Immunohistochemical localization of urokinase-type plasminogen activator system in squamous cell carcinoma of the oral cavity: association with mode of invasion and lymph node metastasis. Oral Oncol 1998; 34: 58-62.

6. Strojan P, Budihna M, Šmid L, Vrhovec I, Škrk J. Urokinase-type plasminogen activator (UPA) and plasminogen activator inhibitor-type I (PAI-1) in tissue and serum of head and neck squamous cell carcinoma patients. Eur J Cancer 1998; 34: 1193-7.

7. Maurizi M, Almadori G, Cadoni G, et al. Cathepsin D concentration in primary laryngeal cancer: correlation with clinicopathological parameters, EGRF status and prognosis. Int J Cancer 1996; 69: 105-9.

8. Lazaris AC, Lendari I, Kavantzas N, et al. Correlation of tumor markers p53, bcl-2 and cathepsin-D with clinicopathologic features and disease-free survival in laryngeal squamous cell carcinoma. Pathol Int 2000; 50: 717-24.

9. Seiwerth S, Stambuk N, Konjevoda P, et al. Immunohistochemical analysis and prognostic value of cathepsin D determination in laryngeal squamous cell carcinoma. J Chem Inf Comput 2000; 40: 545-9.

10. Osmak M, Nikšić D, Brozović A, Ristov AA, Vrhovec I, Škrk J. Drug resistant tumor cells have increased levels of tumor markers for invasion and metastasis. Anticancer Res 1999; 19: 3193-7.

11. Tomasino RM, Morello $\mathrm{V}$, Bazan $\mathrm{V}$, et al. P53 expression in stage III-IV squamous cell carcinoma of the larynx. An immunohistochemical study related to clinico-pathological flow cytometric DNA analysis and prognosis. Int J Oncol 1994; 5: 495-500.

12. Russo A, Bazan V, Gebbia N, et al. Flow cytometric DNA analysis and lysosomal cathepsin B and L in locally advanced laryngeal cancer. Relationship with clinicopathologic parameters and prognostic significance. Cancer 1995; 76: 1757-64.

13. American Joint Committee on Cancer: Larynx. In: Beahrs $\mathrm{OH}$, Henson DE, Hutter TVP, Myers MH, eds. Manual for staging of cancer, Part II, 3rd ed. Philadelphia: JB Lippincott Co, 1988; 39-44.

14. Tumminello FM, Gebbia N, Pizzolanti G, Russo A, Bazan V, Leto G. Cathepsin D content in colorectal cancer. Correlation with cathepsin D activity and other biological parameters: a preliminary report. Oncology 1995; 52: 237-42.

15. Strojan P, Budihna M, Šmid L, Vrhovec I, Škrk J. Urokinase-type plasminogen activator, plasminogen activator inhibitor-type 1 and cathepsin D: analysis of their prognostic significance in squamous cell carcinoma of the head and neck. Anticancer Res 2000; 20: 3975-81.

16. Budihna $M$, Strojan $P$, Šmid $L$, et al. Prognostic value of cathepsins $B, H, L, D$ and their endogenous inhibitors stefin $A$ and $B$ in head and neck carcinoma. Biol Chem Hoppe-Seyler 1996; 377: 385-90.

17. Resnick MJM, Uhlman D, Adams G, et al. Cervical lymph node status and survival in laryngeal carcinoma: prognostic factors. Ann Otol Rhinol Laryngol 1995; 104: 685-94.

18. Goussia A, loachim E, Peschos D, et al. Immunohistochemical expression of cathepsin $\mathrm{D}$ in laryngeal epithelial lesions: correlation with CD44 expression, p53 and Rb status and proliferation associated indices. Anticancer Res 1999; 19: 3055-60.

19. Větvička V, Vetvičková J, Voburka Z, Fusek M. Effects of human procathepsin D on proliferation of human cell lines. Proc Am Ass Cancer Res 2001; 42: 878.

20. Solovyeva NI, Balayevskaya TO, Dilakyan EA, et al. Proteolytic enzymes at various stages of oncogenic transformation of rat fibroblasts. I. Aspartyl and cysteine proteinases. Int J Cancer 1995; 60: 495-500.

21. Tomasino RM, Bazan V, Daniele E, et al. Biological characterization of laryngeal squamous-cell carcinoma. Anticancer Res 1996; 16: 2257-68.

Received: June 8, 2001

Accepted: August 28, 2001 